\title{
A REPRESENTAÇÃO DA NATUREZA EM POEMAS DE PATATIVA DO ASSARÉ
}

\section{THE REPRESENTATION OF NATURE IN PATATIVA DO ASSARÉ'S POEMS}

\author{
Lucicláudia Alves Silva* \\ Naelza Araújo Wanderley ${ }^{* *}$
}

\begin{abstract}
Resumo: A representação da natureza é um dos temas constantes na produção artística, entretanto, pouco se discute essa temática aplicada à Literatura Popular, apesar das muitas recorrências. Dessa forma, objetiva-se elaborar, a partir dessa perspectiva, uma leitura dos poemas "O Sabiá e o Gavião" e "A menina e a cajazeira", de Patativa do Assaré, um dos principais representantes dessa literatura no Brasil. Essa leitura está direcionada para a representação da natureza enquanto tema recorrente em boa parte da obra do referido poeta, estabelecendo uma relação de cumplicidade entre homem e natureza. Essa poesia é marcada de profundo lirismo, através da qual, na maioria das vezes, os elementos da natureza funcionam com uma espécie de suporte para a construção e a expressão desse lirismo.
\end{abstract}

Palavras-chave: Natureza. Literatura Popular. Patativa do Assaré.

\begin{abstract}
Representation of nature is one of the constant themes in artistic production; however, it is scarcely discussed when applied to Popular Literature, despite its recurrent mention in this type of literature. For that reason, we elaborated, from this perspective, a reading of Patativa do Assaré's poems “O Sabiá e o Gavião' and "A menina e a cajazêra", one of the main representative poets of this type of literature in Brazil. This reading is directed to the representation of nature as a recurring theme in much of the poet's work, establishing a relationship of complicity between man and nature. This poetry is marked by deep lyricism, through which, most of the time, the elements of nature work with a kind of support for the construction and expression of this lyricism.
\end{abstract}

Keywords: Nature. Popular Literature. Patativa do Assaré.

\section{Introdução}

A representação da natureza é um dos temas mais recorrentes na produção artística através dos séculos. De acordo com Ribon (1991, p.89), “A natureza nunca é uma exterioridade inerte, e a percepção que o artista tem dela jamais é neutra ou indiferente." No que diz respeito a essa temática, a Literatura Popular, apesar de apresentar inúmeros poemas em que o espaço da natureza constitui-se fundamento para a exposição de vivências e experiências e para a composição de representações e linguagem, não conta com muitos estudos direcionados para essa abordagem.

Observa-se que a maioria das manifestações artísticas, ao serem classificadas como "populares", não recebem a sua devida atenção, sobretudo no âmbito dos estudos acadêmicos. No entanto, isto tem mudado bastante nos últimos anos e é o que acontece com a Literatura Popular. Até bem pouco tempo, era identificada como "marginal” essa

\footnotetext{
* Graduada em Letras-Português pela Universidade Federal de Campina Grande (UFCG) em 2015. cursa Especialização em Educação para as Relações Étnico-Raciais (UFCG) e Mestrado no programa de PósGraduação em Linguagem e Ensino (UFCG). E-mail: luciclaudia.inacio@ hotmail.com

** Graduação em Licenciatura plena em Letras pela Faculdade de Filosofia, Ciências e Letras de Patos (1992), Especialização em Metodologia do Ensino Superior pela Fundação Francisco Mascarenhas / UFPB (1996), mestrado em Letras pela Universidade Federal da Paraíba (2001), doutorado em Letras pela Universidade Federal da Paraíba (2005) e pós-doutorado na área de Letras pela Universidade Federal de Pernambuco (2007). Professora da Universidade Federal de Campina Grande. E-mail: naelzanobrega@ig.com.br
} 
literatura que, hoje, passa a ser reconhecida pelos seus leitores e estudiosos, entre outros aspectos, pela sua variedade temática e riqueza expressiva apresentada.

Referindo-se à literatura popular, Ayala (2003, p. 106-107) afirma que

Quando se estuda a cultura popular ou a literatura popular (oral ou escrita), a meu ver, se nos preocuparmos apenas com os objetos culturais (textos literários, adereços, instrumentos, objetos utilitários, por exemplo), deixando em segundo plano as pessoas, seus modos de vida e o sentido que tem para elas o universo cultural do qual participam, poderemos deixar de perceber os contrastes, as relações, as diferentes temporalidades que mantêm essa cultura viva e presente. Afinal, é sempre um fazer dentro da vida, como o trabalho, a festa.

A autora ressalta a importância de se valorizar o meio em que as pessoas envolvidas no estudo estão inseridas, englobando as suas crenças, seus costumes, enfim, seu modo particular de viver. Dessa forma, o presente estudo não poderia desconsiderar a influência que o sertão nordestino e a sua natureza exercem diretamente na vida dos homens que o habitam.

Assim sendo, com o propósito de sequenciar os estudos sobre a poesia popular, propõe-se aqui o desenvolvimento de uma leitura de poemas de Antônio Gonçalves da Silva, mais conhecido como Patativa do Assaré, a partir da observação da recorrência ao tema da natureza e suas representações em alguns poemas desse autor.

Esse poeta, nascido no Ceará, trabalhou na lavoura por toda a sua existência, vivenciando a realidade dura do agricultor sertanejo. Possui uma obra vasta e riquíssima, que nasce da sua própria experiência no sertão. Publicou seus poemas em livros, o que contribui para que a crítica o defina como um poeta popular e não propriamente como um cordelista.

Os poemas selecionados para a leitura a seguir foram os intitulados "O Sabiá e o Gavião" e "A menina e a cajazeira". Eles apresentam a natureza como uma espécie de moldura que envolve o estado de espírito dos "personagens" do sertão e que aponta tanto para os elementos comuns dessa, quanto para aqueles encontrados em outras regiões e realidades brasileiras.

\section{0 poeta popular Patativa do Assaré}

Em uma entrevista, o poeta Patativa do Assaré afirmou que cultivava o hábito de ler durante as horas em que não estava trabalhando na roça. A leitura foi uma de suas maiores distrações, segundo ele mesmo afirma: "Eu fui apenas alfabetizado. Agora fui um leitor assíduo, cuidadoso, curioso pra saber das coisas. Aprendi a ler, queria ler tudo. (...) lia revista, jornal, os poetas da língua e muitas outras cosa viu? Até Camões, aquele "Os Lusíadas", de Camões, que é uma coisa intrincada."(CARVALHO, 2000 , p. 18 19).

De origem bastante modesta, Patativa adentra o mundo da literatura através da leitura de folhetos de cordel e do contato com os violeiros e repentistas nordestinos. Desde cedo, começou a escrever seus "versinhos" e a recitá-los para a distração de seu povo. Seus versos têm como tema o sertão, ora celebrado por suas grandezas, ora pelas suas misérias, mas sempre o sertão e o sentimento de pertencimento ao lugar. Sua poesia "tem o cheiro / Da poeira do Sertão / Quando passa um ano inteiro / Sem cair 
chuva no chão." (ASSARÉ, 1970, p. 110). Observe-se aqui o poema "Eu e o sertão", do livro Cante lá que eu canto cá:

Sertão, arguém te cantô

Eu sempre tenho cantado

E ainda cantando tô,

Pruquê, meu torrão amado,

Munto te prezo, te quero

E vejo qui os teus mistero

Ninguém sabe decifrá.

A tua beleza é tanta,

Qui o poeta canta, canta,

E inda fica o qui cantá.

(ASSARÉ, 1999, p.21)

Inserida no quadro que compõe o sertão de Patativa está a serra de Santana. É a partir dela que o poeta traduz o sertão e sua natureza, de onde brotam seus versos.

Cresci entre os campos belos

De minha adorada Serra

Compondo versos singelos

Brotados da própria terra,

Inspirado nos primores

Dos campos com suas flores

De variados formatos

Que pra mim são obras-primas,

Sem nunca invejar as rimas

Dos poetas literatos.

(ASSARÉ, 2012, p.21)

Um homem que desde cedo conviveu com o sentimento de perda (a visão, e o pai) e, sobretudo, a pobreza absoluta, aprende logo sobre "as dores do mundo" e, através da poesia, assume o seu papel de mediador entre as dores sofridas pelo seu povo e o mundo, que precisava conhecê-las, mesmo que fosse através do canto triste de seus versos acompanhado da viola, nos alpendres nordestinos, ou na voz de outros cantores em outros ritmos, em outras terras.

Sobre o ato de sua criação poética,

Patativa nos sugere esse estado embrionário, espécie de limbo onde o poema é gestado. É a memória que prevalece, memória que deixa de ser pura sedimentação, para ser o processo em que as conexões são feitas, em que a sensibilidade aflora, em que a voz poética se articula e em que o poema brota.

$[\ldots]$

Patativa fala de sua criação durante as tarefas no campo. Diz que enquanto trabalhava a terra o poema ganhava corpo, que não gosta de ser interrompido, que pedia para que ninguém interferisse em sua concentração, nessa espécie de transe racional, de mergulho no mais fundo de nossa condição humana, de meditação às avessas, onde o absoluto é buscado, não enquanto esvaziamento, mas enquanto plenitude, que se perfaz num jogo mais amplo em que todo o corpo se envolve. 
(CARVALHO, 1999, p. 130).

Autor de uma poesia marcada pela oralidade e pela regionalidade de sua linguagem e de seus temas, mantém em seus poemas o vínculo com a tradição dos folhetos de cordel em seus muitos aspectos, entre eles, a narratividade que conta sobre o sertão e suas paisagens, suas belezas, sobre o sertanejo e sua história e também sobre o seu fazer poético. O poema "Canta lá que eu canto cá" revela ao leitor, através de uma linguagem próxima dos modos de contar do povo, desde os temas mais comuns do dia a dia do sertanejo até a matéria em que forjada a sua poesia.

Poeta, cantô da rua,

Que na cidade nasceu,

Cante a cidade que é sua,

Que eu canto o sertão que é meu.

(...)

Você é munto ditoso,

Sabe lê, sabe escrevê,

Pois vá cantando o seu gozo,

Que eu canto meu padecê.

Inquanto a felicidade

Você canta na cidade,

Cá no sertão eu infrento

A fome, a dô e a misera.

Pra sê poeta divera,

Precisa tê sofrimento.

(...)

Canto as fulô e os abróio

Com todas coisa daqui:

Pra toda parte que eu óio

Vejo um verso se bulí.

Se as vez andando no vale

Atrás de curá meus male

Quero repará pra serra,

Assim que eu óio pra cima,

Vejo um diluve de rima

Caindo inriba da terra.

Mas tudo é rima rastêra

De fruita de jatobá,

De fôia de gamelêra

E fulô de trapiá,

De canto de passarinho

E da poêra do caminho,

Quando a ventania vem,

Pois você já tá ciente:

Nossa vida é deferente

E nosso verso também.

(ASSARÉ, 1999, p. 25-28) 


\section{A natureza na poesia de Patativa do Assaré}

A representação da natureza, associada aos mais diversos temas, é uma constante na literatura desde sempre. Coutinho (1997), ao comentar sobre essa abordagem, evidencia a natureza e os seus diferentes nuances enquanto temática associada aos mais diferentes aspectos a serem apresentados pelo poeta / escritor. Segundo o autor, durante o Romantismo, “[...] a Natureza era um lugar de refúgio, puro, não contaminado pela sociedade, lugar de cura física e espiritual. A natureza era a fonte de inspiração, guia, proteção amiga." (COUTINHO, 1997, p. 9)

Observe-se aqui uma exaltação à natureza que é santificada. Tal aspecto também pode ser identificado na poesia de Patativa do Assaré em vários de seus poemas. Na obra do poeta, é possível verificar essa característica, uma vez que o espaço/ sertão se encontra em comunhão com o estado de espírito dos seus "personagens". "A natureza em Patativa é espaço, tempo e matéria." (CARVALHO, 1999, p. 131). A natureza sertaneja é um livro aberto para a leitura do poeta.

Eu nasci ouvindo os cantos das aves de minha serra e vendo os belos encantos que a mata bonita encerra foi ali que eu fui crescendo fui vendo e fui aprendendo no livro da natureza onde Deus é mais visível o coração mais sensível e a vida tem mais pureza.

Sem poder fazer escolhas de livro artificial estudei nas lindas folhas do meu livro natural e, assim, longe da cidade lendo nessa faculdade que tem todos os sinais com esses estudos meus aprendi amar a Deus na vida dos animais. (ASSARÉ, 2012, p. 20)

Segundo Carvalho (1999, p. 129), a natureza em Patativa do Assaré se funde ao homem de forma que

Em Antonio Gonçalves da Silva, natureza não é apenas um jardim ou a ordem do que está ao nosso redor e onde nos inserimos. Neste sentido, seu discurso é ecológico "avant la lettre", ao propor a fusão do homem com a natureza, a integração de duas ordens que poderiam parecer complementares e que, em sua poética, se soldam na constituição de uma liga.

$[\ldots]$

Essa integração do homem com a natureza e, por conseguinte, da natureza com a cultura pode ser também compreendida como a 
vivência aprofundada e amadurecida de um tardio romantismo que idealizava o natural como um valor intangível.

CARVALHO (1999, p. 129)

Observe-se o poema intitulado "O sabiá e o gavião", de Patativa do Assaré. Quanto aos elementos estruturais, é composto por vinte e quatro estrofes de dez versos de sete sílabas cada. Em praticamente todas as estrofes, é possível identificar a referência à natureza do sertão, seja para descrever o ambiente, o estado de espírito dos personagens ou ainda para personificá-la.

$\mathrm{Na}$ descrição do ambiente, "o juazêro", esse "personagem" impetuoso do sertão, é fonte de aconchego, mesmo em meio a mais cruel das secas, uma vez que ele se mantém verde e acolhedor, não somente para o homem, mas também para os pássaros, responsáveis pelo canto. O poeta referencia, no poema, conhecidos pássaros canoros do sertão, como o galo de campina, a patativa, o "canaro" e o sabiá, que é "dos musgo da pena / O maior do mundo intêro". O pequeno prazer proporcionado ao homem pela poesia e melodia do canto do sertão pode ser comparado ao canto "Dos anjo celestiá". A natureza aqui aproxima o sertanejo do aspecto divino e funciona como elemento de confirmação de uma fé tão característica.

A coisa mió que eu acho

É num dia munto quento

Eu i me sentá debaxo

De um copado juazêro,

Pra escutá prazentêro

Os passarinho cantá,

Pois aquela poesia

Tem a mesma melodia

Dos anjo celestiá.

(ASSARÉ, 1999, p. 226)

A seguir, o poeta evidencia, através da referência aos elementos da natureza, como, da mesma forma que existem pássaros que refletem a mão divina da criação no sertão, também existem aqueles que representam o mal, uma vez que existe o "gavião maldito", "o assassino das ave", feito por um "Diabo munto inxerido". Ou seja, para cada criação divina de beleza, o Diabo, "escondido", encontra uma maneira de criar a oposição, assim como na vida de todos os seres.

Quanto à relação da natureza e do estado de espírito dos personagens do sertão, é possível observar, nas estrofes abaixo, inicialmente, a referência a um cenário que inspira a alegria do encontro do ninho para, logo a seguir, surgir a descrição de um cenário que anuncia a tristeza em todas as suas nuances:

Quando eu era pequenino,

Saí um dia a vagá

Pelos mato sem destino,

Cheio de vida a iscutá

A mais subrime beleza

Das musga da natureza

E bem no pé de um serrote

Achei num pé de juá

Um ninho de sabiá 
Com dois mimoso fiote.

(ASSARÉ, 1999, p. 228)

$$
(\ldots)
$$

Na copa dos arvoredo, Passarinho não cantava. Naquele dia, bem cedo, Somente a coã mandava Sua cantiga medonha. A menhã tava tristonha Como a casa de viúva, Sem prazê, sem alegria E de quando em vez, caía Um sereninho de chuva. (ASSARÉ, 1999, p. 229)

Em ambas as estrofes acima, podemos verificar que a natureza acompanha o estado de espírito do personagem. A primeira estrofe descreve o dia em que o menino encontrou o ninho com os filhotes de sabiá. Já a segunda diz respeito ao momento em que o menino saiu de casa e descobriu que o gavião havia comido os dois sabiás. Os mesmos passarinhos que antes faziam "A mais subrime beleza/Das musga da natureza" dão lugar à "cantiga medonha" da "coã", acompanhada de uma manhã tristonha. Podese observar, ainda, em algumas passagens no poema, uma característica muito próxima daquela que a crítica literária, durante o Romantismo, chamou de culto à natureza.

Todo o poema se estrutura de forma que a natureza e os elementos que a compõem refletem, não somente o cenário onde os fatos são narrados, mas um conjunto de elementos narrativos que, não somente permitem ao leitor conhecer os fatos, mas senti-los nos componentes citados, tão próximos da realidade do nordestino. Um exemplo desse aspecto da poesia de Patativa pode ser observado na constante referência aos pássaros, em especial ao sabiá, sempre cantado pelo poeta que o considera o "chefe dos seresteros". Ele representa a alegria e o canto do sertão, mesmo em meio às suas tristezas. O seu canto é festa para a natureza e para os ouvidos do homem que escuta atentamente os sons da terra.

No poema intitulado "A menina e a cajazeira", que é composto por vinte e uma estrofes de dez versos de sete sílabas cada. Praticamente, todas as estrofes apresentam alguma referência à natureza, seja para descrever o ambiente, o estado de espírito dos personagens ou até mesmo utilizá-la como reflexo dos fenômenos que rodeiam a existência e o destino humano.

Inicialmente, o poema fala sobre a efemeridade dos momentos de felicidade e prazer, passageiros "cumo o relampo" para o homem. Após o pecado de "Adão mais Eva", "A rosa criou espinho". Observe-se aqui mais uma referência, que continua ao longo do poema, ao forte contexto de religiosidade, assim como a citação dos elementos da natureza para ilustrar aspectos da existência dos homens, pois, após o pecado, o Deus criador "uma parcela de dô / Reservou pra cada um.". É com esse esclarecimento nas estrofes iniciais que o poeta anuncia a narrativa da "Triste e penosa histora / Da menina e a cajazêra.".

Num sito munto distante, 
Na bêra de uma lagoa,

Morava um casá fié,

Uma gente munto boa.

Tinha uma linda criança,

Risonha cumo a esperança,

Era linda e prazêntera.

E brincava todo o dia

Na sombra fresca e sadia

De uma bela cajazêra.

(ASSARÉ, 1999, p. 196-197)

Os dois elementos da natureza que aparecem nesta estrofe são o lago e a "cajazêra", ambos possuem a mesma função de compor o ambiente rural em que a família da menina morava, assim como traduzir a harmoniosa convivência entre o ser o e o meio que habitava. A "cajazêra" aparece com uma "sombra fresca e sadia", ou seja, o bem-estar da criança também é expandido ao da árvore. Esse momento do poema conta sobre a possibilidade de um "Paraíso" na terra, proporcionado pela perfeita convivência entre homem e natureza:
Aquela copa vistosa
Pra inocente criança
Era um céu, um paraíso
Verde da cô de esperança.
As aves fazia festa,
Tinha graça a doce orquestra
Daqueles musgo de pena,
Com seus requebrado canto,
Lovando o riso e o encanto
Daquela santa pequena.
(ASSARÉ, 1999, p. 197)

Já na estrofe a seguir, após a narração dos acontecimentos que representam, na narrativa, a chegada do "vento da negra sorte", mais uma vez, a natureza compõe o cenário e reflete com suas cores e ações o que sente o homem. Temos uma representação poética de uma integração profunda entre o ser e o meio em que habita.

Foi-se embora saluçando

Aquela criança boa,

Dexando luto e tristeza

Lá na bêra da lagoa.

E a cajazêra copada

Vendo a sua camarada

Da sombra se retirá.

Levando o pranto no rosto,

De tanto sofrê desgosto

Nunca mais botou cajá.

(ASSARÉ, 1999, p. 199) 
Nesta estrofe, além de conter uma extensão da tristeza da menina, a "cajazêra", metaforicamente personificada pelo narrador, assimila de tal forma o desgosto de sua companheira que definha diante da ausência. Essa personificação persiste até o fim do poema como forma de ilustração da relação homem / natureza. Nos versos a seguir, novamente, é possível observar, na poesia de Patativa, elementos como o canto "triste da coã” em substituição ao canto alegre de outros pássaros e o aspecto de sombras como substituição do claro e da alegria antes vivenciada.

No gaio, onde os passarinho

Gorjeava de menhã,

Ficou cantando somente

A feia e triste coã.

E de noite o vento afoito,

Roncando e lhe dando açoito,

Formava uma entonação

De causá medonho espanto,

Acompanhada do canto

Do agorento corujão.

(ASSARÉ, 1999, p. 200)

Nesta estrofe, o vento assume o papel de acompanhar o estado de espírito dos personagens, por isso, ora surge "macio e brando", ora vem afoito "Roncando e lhe dando açoito". A separação entre a menina e a cajazeira funciona como uma espécie de marco divisor no poema, não somente entre a alegria e a tristeza da menina, mas também da "cajazêra" e de todos os elementos da natureza que compõem a moldura do ambiente. Essa mudança também pode ser identificada em outros elementos do poema, como a lagoa e os passarinhos:

Inté a prope lagoa

Perdeu a quilaridade,

Criou nas água uma sombra

Roxa, da cô da sodade.

Tudo neste mundo passa,

O sito perdeu a graça,

Daquele sonho de amô

Hoje ali já nada existe,

Apenas o choro triste

Da rola fogo-pagou.

(ASSARÉ, 1999, p. 201)

A lagoa muda a cor de suas águas, e os passarinhos que, outrora, cantavam alegres nos galhos da "cajazêra", dão lugar ao " choro triste" da rola fogo-pagou. Aqui, a dor da saudade e ausência sentidas tanto pela menina quanto pela natureza que compõe o ambiente, principalmente a "cajazêra", refletem, mais uma vez, a forte integração entre o habitante do sertão e sua terra, pois, se o homem do sertão tem a sua existência e as suas dores vinculadas à sua terra, também ela definha com a ausência de seus filhos. 


\section{Considerações finais}

As leituras aqui elaboradas acerca dos poemas "O Sabiá e o Gavião" e "A menina e a cajazeira" possibilitaram a observação de uma representação da natureza sempre presente nos referidos poemas de Patativa do Assaré, assim como em boa parte de sua obra. Essa característica estabelece uma relação de cumplicidade entre homem e natureza na descrição de ambientes, na apresentação do estado de espírito dos personagens e até mesmo como representação de um vínculo entre o sentimento de religiosidade e a realização deste, tendo como base a perfeita convivência entre o homem do sertão e a natureza que o cerca, permitindo-lhe, até mesmo, através desta, encontrar na terra o paraíso embaixo de uma copa de juazeiro ou de uma cajazeira.

$\mathrm{Na}$ poesia de Patativa, pode-se reconhecer, entre as características e temáticas encontradas, uma espécie de culto à natureza, muito próximo daquele apresentado pelos autores do Romantismo, assim como um certo sentimento de pessimismo e morbidez representados também por elementos e cores da natureza. Estes temas se fazem presentes, de uma maneira detalhada e riquíssima, na composição dos ambientes dos poemas desse autor.

Cabe ainda lembrar que, apesar de não se voltar especificamente para a produção lírica, em seus versos, o poeta apresenta passagens de profundo lirismo, em que, na maioria das vezes, também serão os elementos da natureza o grande suporte para a construção e expressão desse lirismo.

\section{Referências}

ASSARÉ, Patativa do. Patativa do Assaré. Org. J. de Figueiredo Filho. Fortaleza: Universidade Federal do Ceará, 1970.

ASSARÉ, Patativa do. Cante lá que eu canto cá: filosofia de um trovador nordestino. 9.ed. Petrópolis: Vozes, 1999.

ASSARÉ, Patativa. A menina e a cajazeira. In: ASSARÉ, Patativa do. Cante lá que eu canto cá: filosofia de um trovador nordestino.16.ed. Petrópolis: Vozes, 2011.

ASSARÉ, Patativa. O sabiá e o gavião. In: ASSARÉ, Patativa do. Cante lá que eu canto cá: filosofia de um trovador nordestino.16.ed. Petrópolis: Vozes, 2011.

ASSARÉ, Patativa. Ispinho e fulô. São Paulo: Hedra, 2012.

AYALA, Maria Ignez Novais. Aprendendo a aprender a cultura popular. In: PINHEIRO, Helder. (Org.) Pesquisa em literatura. Campina Grande: Bagagem, 2003.

CARVALHO, Gilmar de. Patativa do Assaré: natureza e cultura. Revista do GELNE. Ano 1, No2, 1999.

CARVAlHO, Gilmar de. Patativa Poeta Pássaro do Assaré. Fortaleza: Editora Inside Brasil Ltda., 2002. 
COUTINHO, Afrânio.(org.) .A literatura no Brasil- Era Romântica. 4. ed. rev. e atual.São Paulo: Global, 1997.

RIBON, Michel. A arte e a natureza. São Paulo: Papirus, 1991.

Recebido em 28 de julho de 2019

Aceito em 05 de dezembro de 2019 